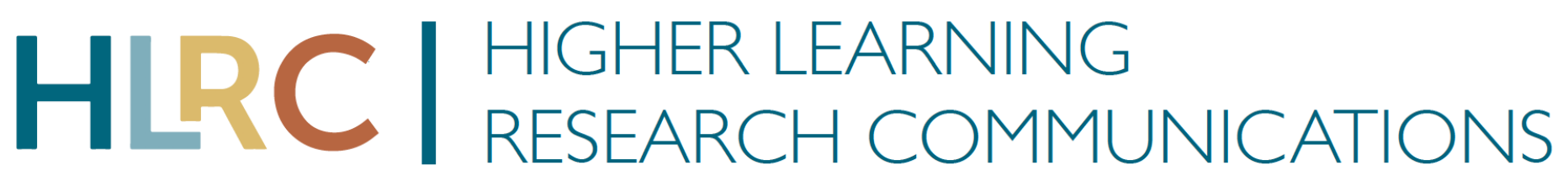

Higher Learning Research Communications

2020, Volume 10, Issue 1, Pages 78-89. DOI: 10.18870/hlrc.v10i1.1170

\title{
Online Doctoral Student Research and Writing Self-Efficacy in a Publishing Internship
}

\author{
Lee M. Stadtlander, $\mathrm{PhD}$
}

Walden University, Minneapolis, Minnesota, United States

(iD) https://orcid.org/0000-0002-8149-7236

Amy Sickel, $\mathrm{PhD}$

Walden University, Minneapolis, Minnesota, United States

(iD https://orcid.org/0000-0001-7229-3509

Daniel Salter, $\mathrm{PhD}$

Walden University, Minneapolis, Minnesota, United States

(iD) https://orcid.org/0000-0001-9854-8362

Contact: leann.stadtlander@mail.waldenu.edu

\begin{abstract}
The present project proposed to develop a publishing internship program and evaluate its effect on doctoral student participants. A key assumption was that direct experience with the publishing process as a doctoral student would help build some of the necessary skills and self-efficacy to be successful as authors/scholars in the future. Because there has not been previous research in this area, the present study addresses this gap. Two different assessments, a writing knowledge and self-efficacy inventory and a research self-efficacy inventory, were used in a pre-posttest design to evaluate the impact of participation in the 6-month internship program on 22 online doctoral students. A texting app was used to build a community of practice to provide social support. Writing self-efficacy and research self-efficacy improved significantly over the 6month internship. Students judged the internship favorably and found the texting group to offer social support and information. Programs such as the current journal internship may offer the opportunity for students to gain valuable professional experience and learn the logistics of journal publishing, thus potentially allowing for better dissemination of doctoral research. This article contributes a mechanism for increasing students' understanding of the publication process, as well as improving research and writing self-efficacy. Future research may wish to explore the impact of technology and texting groups on student research selfefficacy and feelings of social support.
\end{abstract}

Keywords: doctoral writing; publication; doctoral internship; community of practice; self-efficacy

Submitted: February 25, 2020 | Accepted: May 6, 2020 | Published: May 26, 2020

\section{Recommended Citation}

Stadtlander, L. M., Sickel, A., \& Salter, D. (2020). Online doctoral student research and writing self-efficacy in a publishing internship. Higher Learning Research Communication, 10(1), 78-89. DOI: $10.18870 /$ hlrc.v10i1.1170

Note: This research was supported in part by funds received from a Hybrid Teaching \& Learning Research Grant, which was created by the Research Office in the Academic Quality and Accreditation Unit of the Laureate Network Office to support research that investigates the impact of digital teaching and learning methods on learning outcomes. For more information on the grant or the Laureate Network Office Research Office, please contact LNOResearch@laureate.net. 


\section{Literature Review}

The doctoral dissertation (which may be called a "doctoral thesis," doctoral project," or "capstone" in some institutions) demonstrates students' abilities to conduct an original piece of empirical research as part of the requirements of doctoral programs (e.g., EdD, PhD; Cone \& Foster, 2006; Walder et al., 2008). Students must demonstrate their learning from their graduate education to create an original contribution to the research literature. This expectation requires a change from the student role of course-taker to that of knowledgecreator, which can be difficult (Breitenbach, 2019). The perceived difficulty of completing a dissertation is probably most evident in the hundreds of books written on the subject that apparently are not supporting students effectively (Kamler \& Thomson, 2008). A dissertation is more than just a writing exercise. It involves research skills, persistence, the ability to deal with stress, functioning independently, and working well with others (Brennan, 2018). Student success also relies on the perception of his or her own ability to accomplish these tasks. Therefore, the notion of self-efficacy is the focus of this grant-supported study on the development and evaluation of a program to help build students' capacities to complete the dissertation.

Specifically, the present study addressed the challenges inherent to doctoral education and the dissertation through the development of a doctoral internship program to support the university's professional journals and to support the interns through a virtual community of practice. A key assumption was that for a doctoral student, direct experience with the publishing process would help reinforce writing skills as well as research self-efficacy. Enhanced writing skills and research efficacy may support students in completing their dissertation and meeting publishing demands potentially required for future academic faculty positions (Stoilescu \& McDougall, 2010). We could find no studies where publishing experience had been tested, although many authors have supported the broader strategy of providing targeted support. In the present project, we take advantage of mobile technologies to help address the isolation challenges inherent to training scholars from online educational institutions (Rockinson-Szapkiw et al., 2016) and address the writing and research skills and self-efficacy that should help them to graduate.

\section{Social Cognitive Theory}

The current project is based upon social cognitive theory (Bandura, 1986), which postulates that learning happens in a dynamic environment in which the person interacts and changes their behavior as needed. One central aspect of Bandura's social cognitive theory is self-efficacy, which is the level of a person's confidence in his or her ability to perform a behavior successfully (Bandura, 1986, 1993; Bandura et al., 1996). Bandura (2006) also indicated that self-efficacy is not a fixed attribute. Rather, this capability relies upon cognitive, motivational, emotional, and behavioral skills that change over time and in different situations. Given the goal of training researchers who can function independently (Gardner, 2009), development of self-efficacy has emerged as a key component of the doctoral student experience and thus grounded this study.

People with high self-efficacy are more likely to take on challenges, try harder, and persist longer than those with low self-efficacy (Bandura, 1989); they also tend to be less apprehensive and reduce their anxiety by approaching situations directly. In contrast, individuals with low self-efficacy avoid anxiety-producing situations (Pajares, 1997). As self-efficacy is a dynamic construct made up of multiple dimensions, it is necessary to evaluate its features in different activities (Bruning et al., 2013). In the current study, these activities consist of doctoral writing and research skills.

\section{Writing self-efficacy}

High writing self-efficacy leads to better writing and less anxiety about the process of writing compared to individuals with low writing efficacy (e.g., Lavelle, 2006; McCarthy et al., 1985; Pajares \& Valiante, 1999). Although previous research has tended to examine the $\mathrm{K}-12$ and undergraduate levels of writing efficacy (Sanders-Reio et al., 2014), a few studies have addressed the issue on a graduate level (e.g., Aitchison, 2009; Kozar et al., 2015; Plakhotnik \& Rocco, 2016). An important aspect of earning a research doctorate is learning 
to write like a scholar: The writing required in the dissertation is a new and more challenging form of academic writing than the student has previously experienced (and may have mastered) in coursework. Thus, entering the dissertation phase of their graduate program tends to increase students' anxiety and challenge their writing self-efficacy (Russell-Pinson \& Harris, 2017).

\section{Research self-efficacy}

Research self-efficacy is an individual's beliefs in his or her ability to perform research-related tasks, such as conducting research studies and disseminating the findings. Previous studies on research self-efficacy has focused on the precursors (e.g., interest in research) or the outcomes of competencies (e.g., research productivity) rather than the actual competence and skills of the researcher (Bieschke, 2006; also see Lambie et al., 2016).

Within the research on the role of doctoral self-efficacy, some researchers have examined strategies to support development of it in doctoral students. These studies have focused on the mentoring provided by faculty (e.g., Lev et al., 2010; Overall et al., 2011), the interactions with other students in various types of communities (e.g., Shea \& Bidjerano, 2010), specialized workshops (Ford, 2010), and the provision of more early research experiences (Love et al., 2007). The current study builds off those strategies by providing online doctoral candidates with mentoring by journal editors and peer interactions within a virtual community.

\section{Social Connectedness}

Interpersonal interaction is key to building self-efficacy (Bandura, 1986). In one form, bringing doctoral students together in a community of practice increases social connectivity, is associated with higher levels of doctoral degree completion (Breitenbach, 2019; Lloyd et al., 2016; Rockinson-Szapkiw et al., 2016), and has been found to help students with their writing and progress in their programs (Lassig et al., 2013). Such groups have been described as a method to change doctoral learning into a social experience and to shift focus from the relationship with faculty supervisors to that of peers (Baker \& Lattuca, 2010; Maher et al., 2008). Communities of practice (a) increase social connectivity through a shared commitment to achieve writing and scholarly competence (Wenger, 1998; Wenger \& Snyder, 2000). (b) They form a supportive environment that includes academic, social, and emotional support; build relationships with diverse people; and promote mutual trust (Lassig et al., 2013). (c) The group brings a sense of community and encourages the identity as a scholar (Lassig et al., 2013). Such doctoral communities, described in the literature, tend to be in-person groups meeting at regular times. Kozar et al. (2015) demonstrated the efficacy of such a doctoral group online. The present study extended their work by developing a virtual community of scholarly practice using the digital technology of group texting and conferencing software.

\section{Purpose of the Study and Research Questions}

Despite the career path of going into professional (and perhaps academic) positions, the prospect of writing for publication produces anxiety among graduate and postgraduate students who find the processes involved in becoming published to be mysterious and difficult (Cuthbert \& Spark, 2008; Kamler, 2008; Lassig et al., 2013; Russell-Pinson \& Harris, 2017). In keeping with the theory and research around anxiety reduction (Treanor \& Barry, 2017) and development of self-efficacy (Lev et al., 2010; Overall et al., 2011), we assumed that a structured experience about the publication process would increase students' knowledge of the process and improve interns' research skills, writing knowledge, and self-efficacy related to scholarly writing. Because we were unable to identify an existing model for the problem, we sought grant funding to develop this internship program to fit the overall context of our university.

A 6-month internship program was developed in which student interns had the opportunity to review manuscripts submitted to the journals, attend training webinars, and participate in a texting group with other interns. Students were unpaid and did not receive course credit for their participation. The managing editors 
of the university academic journals were recruited to work directly with the interns and investigators in this study. The editors initially provided two previously masked-reviewed manuscripts, this served as a training exercise for the interns. Later, four newly submitted manuscripts were reviewed, in which the interns served as primary peer reviewers for the journal. The doctoral interns were asked to review manuscripts every 4 weeks, a total of six reviews for each intern. Following each review, the students critiqued the reviews of other interns and the journals' peer reviewers as compared to their own reviews. This added assignment provided the opportunity for students to assess what other peer reviewers reported as problems in the manuscript and to see how others wrote and presented their reviews.

The interns also came together as a virtual community in two ways. First, they met monthly in a virtual training environment (using GoToMeeting conferencing software; see https://www.gotomeeting.com) with instructors (the principal investigator [PI] and co-PIs). During these monthly meetings, interns were taught techniques for reviewing journal articles, had the opportunity to ask questions regarding the review process, discussed final evaluations of articles they reviewed, and interacted with their peer group of interns. Second, interns were given access to the group texting app GroupMe (Hecht \& Martocci, 2010), which allowed students to interact as a virtual community in a texting environment. In the texting group, students discussed problems and questions that arose during their internship experience. The PI, as group facilitator, provided daily prompts to get the discussions started (e.g., "How is your review coming along?") and helped the students relate their intern experience to their dissertation process (e.g., "How would you handle the problems that the researcher described, if they occurred in your project?”).

\section{Research Questions}

To evaluate whether this program had the intended impact, six research questions were developed:

Research Question 1: Is there a change in interns' research self-efficacy between the start and end of the 6-month internship?

Research Question 2: Is there a change in interns' writing knowledge between the start and end of the 6month internship?

Research Question 3: Is there a change in interns' writing efficacy between the start and end of the 6month internship?

Research Question 4: How do students rate the internship overall, on a scale from 1 (I don't like it) to 10 (I love it)?

Research Question 5: For what purposes do students report using the GroupMe texting app?

Research Question 6: What do interns perceive as the positives and negatives of the internship?

\section{Method}

\section{Participants}

This study was approved by the university's institutional review board (Approval Number 09-15-16-7823852). An announcement describing the internship was placed in all university dissertation classrooms. Students interested in participating completed an online application through SurveyMonkey. Questions were about their program, where they were in the dissertation process, and for which journals they were interested in interning. A total of 284 students from all programs at the large online university applied for the possible 28 positions (seven for each of the four journals). All students expressing interest in a given journal were assigned a random number, and the largest seven random numbers for each journal were selected as interns.

Of the initial group, 22 students completed the internship program, with six eventually dropping out, citing lack of time and family obligations as reasons. Those students who completed the internship included 19 
women and three men; 10 of the interns were self-described as Black, 10 as White, one as Hispanic, and one as Asian. The mean age of the interns was 46.5 years, with a range between 32 and 59 years. The interns' demographics were consistent with the overall university's doctoral student population.

\section{Procedures}

All interns attended a monthly webinar (virtual training) in which issues related to manuscript reviewing were discussed; examples of the topics included the roles of the editors and reviewers and reviewing a study's methods. The interns completed a manuscript review for their assigned journal every 4 weeks, and they completed a critique of their review as compared to all other reviewers' comments. Editors of the journals supervised the interns' performance and provided brief feedback on their reviews. Each editor received a monthly $\$ 50$ gift card for their participation.

All interns were asked to complete two instruments and a survey in SurveyMonkey at the beginning and at 6 months, receiving a $\$ 10$ gift card each time. At the end of the internship, the interns were asked their opinions as to the positives and negatives of participating in the journal internship.

\section{Instrumentation}

Along with a researcher-created evaluation form, which included demographic information, two measurement instruments were used in this study. The Research Appraisal Inventory (RAI: modified; Stadtlander et al., 2013) was used to measure the interns' research self-efficacy. This 46-item measure examines each step in the dissertation/writing process and asks the participants to rate their ability from 1 (beginner) to 5 (expert). As an instrument, scores on the RAI have been consistently correlated with several measures of self-efficacy (Stadtlander \& Sickel, 2017). Example questions on the inventory (following the prompt "I can ... ") are "articulate the rationale for my research idea in terms of an existing gap in the literature" and "recognize important threats to internal and external validity applicable to research designs." Scores may range from a low of 46 to a high of 230. In the current study, Cronbach's alphas were $\alpha_{\text {pre }}=.98$ and $\alpha_{\text {post }}=.98$. This instrument was used to evaluate Research Question 1.

The Doctoral Writing Knowledge and Efficacy Inventory (DWKEI; Stadtlander \& Sickel, 2017) consists of two parts. The multiple-choice writing knowledge portion consists of 42 questions such as the following

(boldface indicates the correct answer):

1) Which is correct?

a) Quotes should be used often in professional writing, as they provide substantiation to points made.

b) Quotes should rarely be used in professional writing, as they tend to distract from the writer's voice.

2) Which is correct about 2 girls?

a) the two girl's bikes

b) the two girls bikes

c) the two girls' bikes

d) the two girls bikes'

The range of scores was from o to 42 and Cronbach's alphas were $\alpha_{\text {pre }}=.62$ and $\alpha_{\text {post }}=.70$. The self-efficacy portion consists of 24 questions (e.g., "I understand the use of citations in APA format" and "I understand the rules for possessives in APA format") rated from 1 (strongly disagree) to 5 (strongly agree), with a range of scores from 24 to 120 and Cronbach's alphas of $\alpha_{\text {pre }}=.92$ and $\alpha_{\text {post }}=.95$. The DWKEI was used to assess writing knowledge in Research Question 2 and writing efficacy in Research Question 3. 
All interns completed a final anonymous evaluation of the internship experience that included three questions. To address Research Question 4, they were asked to rate their internship experiences on a scale from 1 (I don't like it) to 10 (I love it). To address Research Question 5, they were asked, "How often did you use the GroupMe texting app and for what purposes?" The final open-ended questions were "What were the positives of participating in this internship?" and "What were the negatives of participating in this internship?” These items were used to evaluate Research Question 6.

\section{Data Analysis}

As the sample was small, we were unable to run a fuller multivariate analysis. Instead, we relied on a series of paired $t$ tests to examine pre- to posttest change. Because of the potential inflation of Type I error, the a priori alpha level was divided by the number of these analyses $(.01 / 3=.003)$ as a correction for assessing statistical significance. A post hoc power analysis for two-tailed, paired $t$ tests, with $\alpha=.05$ and a sample size of 22, indicated a power of .61. For the qualitative questions, the responses were summarized.

\section{Results}

\section{Research Question 1}

A paired $t$ test of scores on the RAI indicated research self-efficacy improved significantly between pre- $(M=$ $92.8)$ and postinternship $(M=154.5), t(21)=9.29 . p<.001$.

\section{Research Questions 2 and 3}

A paired $t$ test of writing knowledge scores on the DWKEI at pre- $(M=31.8)$ and postinternship $(M=32.9)$ was not significant, but interns' writing self-efficacy for pre- $(M=80.38)$ and postinternship $(M=95.3)$ was significantly improved, $t(20)=6.36, p<.001$.

\section{Research Question 4}

In their final evaluation, the interns rated the internship on a scale from 1 (I don't like it) to 10 (I love it). Scores ranged from 7.5 to 10 , with a mean of 9.4 .

\section{Research Question 5}

Interns were asked if they had used the GroupMe texting app and, if so, for what purposes. They could give more than one response. Eighteen reported using the app at least occasionally. The most frequently reported purpose for using the app was for social support and networking $(n=10)$. Interns also reported using it for more information $(n=8)$ and to keep connected to faculty $(n=8)$.

\section{Research Question 6}

Out of the 22 interns, 19 provided qualitative comments as to the positives and negatives of being an intern. Overall, the comments tended to be positive. Fifteen interns indicated a positive aspect was learning about publishing. Some example comments include "I learned how to understand and critique research, especially quantitative research" and "[The internship] broadened my perspective on research and writing." Six mentioned that they valued being part of a group, for example, "I enjoyed communicating with like-minded people around the country" and "I found new friends during the process." Five mentioned they could relate their training to their dissertation work, for instance, "I learned how to read my own research critically" and "I learned about the publishing process and review process, which has helped improve my own writing skills." 
On the other hand, 10 interns provided at least one negative comment; all were related to keeping up with the time commitments of the internship. For example, one intern wrote, "It was difficult to learn how to manage my time in reading and reviewing each article, while also continuing to work on my own (dissertation) proposal." Another stated, "The internship happened at a time when I had many clashing responsibilities that robbed me of the time I needed to spend on the internship."

\section{Discussion}

Consistent with the goals of the experience, the interns improved on key measures of writing and research self-efficacy, which are constructs that are predictive of later success (Lee \& Kamler, 2008). This improvement is consistent with theory, which indicates that self-efficacy to be the product of four personal resources: direct experiences, indirect experiences, verbal persuasion, and emotional state (Bandura, 1986). These experiences include indirect experiences such as witnessing the writing achievements of others; the verbal comments from family, teachers, or friends about their writing; and the students' feelings about their writing skills due to their current emotional state (Altunkaya \& Topuzkanamış, 2018). Similarly, research self-efficacy is more than an individual's ability to perform research related tasks; it also involves making a cognitive change (i.e., making the paradigm shift to thinking like a scholar-researcher) and making explicit behavior choices (i.e., engaging in research activities; Bandura 1986). Therefore, research and writing self-efficacy can be viewed as including the student's total experiences using his or her own research and writing skills, such as those the interns experienced.

Previous research has reported that students with high writing efficacy tend to write better and be less apprehensive about writing than those with low writing efficacy (e.g., McCarthy et al., 1985; Pajares \& Valiante, 1999). Likewise, research self-efficacy has been found to be predictive of a graduate student's interest in conducting empirical research (Bishop \& Bieschke, 1998). The present study adds to the limited literature on doctoral level writing efficacy (e.g., Aitchison, 2009; Kozar et al., 2015). These results suggest that the interns appear to have gained the confidence needed to work successfully on their dissertations and perhaps submit the research for publication.

The interns did not significantly improve on writing knowledge. The lack of significant findings related to writing knowledge may have been due to the small sample size, complexity of the construct, the DWKEI's operationalization of it, or lack of diversity within the sample group. An alternative may be that while interns had the opportunity to critique others' writing, they may have needed experience and feedback on their own writing performance to improve on the writing knowledge scale. Additional research is warranted in this area.

The internship program was popular with students, as evidenced by the high rating given to the experience (9.4 out of 10), and they indicated that they appreciated the opportunity to learn about publishing and had an awareness of being able to apply the new skills to work on their dissertation. Programs, such as the current journal internship, offer the opportunity for students to gain valuable professional experience and learn the logistics of journal publishing, thus possibly allowing for better dissemination of doctoral research. As a strategy to support student achievement, offering doctoral students a supervised experience in the journal review process, while they are students, seems predictive of their ability to complete their degree and potential success as a scholar afterwards. This approach was logistically challenging, however, and places added burden on journal editors for tasks beyond the traditional editorial role.

Finally, to help improve the research and writing self-efficacy of doctoral students, the journal internship program was developed to provide a community of practice for social interaction while giving students handson editorial experience. The results suggest that these goals were met. The internship showed the viability of a text-based community of practice, extending previous work (Kozar et al., 2015) using online doctoral communities. A text-based community of practice for doctoral scholars opens the possibility of peer support 
to a much wider range of students. The interns also mentioned their appreciation of having faculty be available for questions, suggesting that using faculty-led groups may make the group more dynamic and useful for the student. In the present study the faculty involvement was kept to a few minutes a day unless specific questions were asked, which suggests that faculty workload may not necessarily increase when using the texting group for students. The use of these types of technology solutions may warrant additional future direct study regarding their impact on student research self-efficacy and impact on feelings of social support.

\section{Limitations of the Study}

Several factors limit the generalizability of this preliminary program targeted at supporting doctoral success. More capable and motivated students were likely to have self-selected to participate in this program, so it is unclear whether a similar strategy could support students with a range of abilities. By randomly selecting students, we had hoped to reduce this bias; however, ultimately, the success of this strategy is unknown. Further, six interns did not complete the internship, reporting they lacked the time and mentioned family obligations as reasons.

The four journal editors each managed the interns their own way, which may have impacted interns' outcomes. Some interns reported challenges meeting internship requirements given other time constraints; future programs might consider refining the program if and where possible to alleviate some participant time strain. The present study's interns were not paid, nor did they receive course credit. Providing course credit or a paid internship may increase commitment and reduce the time strain, as students may be better able to integrate the experience into their other commitments.

The overall research design and execution were also limited. The sample was small and did not include a control group, which might have been a way to examine whether the gains the students experienced are truly the result of the internship or if they were a normal occurrence for doctoral students in general. Other measures, including one that specifically addressed performance anxiety, might have provided more insight into the student experience. It is also unclear whether online students have additional constraints that somehow influenced the outcome in ways that do not extend to residential students.

\section{Implications for Research and Theory and/or Practice}

Interventions targeted at supporting self-efficacy have been found effective for some doctoral students, especially those related to research (e.g., Baltes et al., 2010; Overall et al., 2011; Unrau \& Beck, 2004). However, as noted earlier, fewer studies (e.g., Plakhotnik \& Rocco, 2016) have focused on strategies to improve graduate students' perceived ability to write about the research they conduct. The current study is the first to have examined the impact of a publishing internship program on self-efficacy. With the increase in online education delivery, the study also adds to the growing body of research around the technologies used to maintain virtual communities. Although the GroupMe app was selected for this study as an easy-to-use texting solution, other platforms exist, and new ones will surely emerge in the years ahead.

A question not addressed in this study is whether the increased writing efficacy results in more rapid completion of their dissertations by the interns and more subsequent publications as graduates. Additionally, this study did not examine the impact of self-efficacy on student research or writing anxiety. Future researchers may wish to conduct a longitudinal study, following the students' writing progress and success over time, possibly into their postdoctoral careers.

\section{Recommendations}

Other universities may not have the potential to replicate our exact internship; we were fortunate to have easy access to four journals supported by our university, which may not be the case at other institutions. However, it may be possible to develop a modified version of the program in which faculty provide early drafts of their 
own manuscripts. Alternatively, students could review each other's manuscripts that they hope to publish. It may even be beneficial for students to review published articles or unpublished manuscripts posted on ResearchGate (researchgate.net) or Google Scholar (scholar.google.com) and explore the criteria that peer reviewers may use for their critique.

\section{Conclusions}

As a strategy to support student achievement, offering doctoral students a supervised experience in the journal review process, while they are students, would appear to be supportive of students' abilities to complete their degree and potential success as a scholar afterwards. This approach was logistically challenging, however, and placed added burdens on journal editors for tasks beyond the traditional editorial role.

\section{References}

Aitchison, C. (2009). Writing groups for doctoral education. Studies in Higher Education, 34, 905-916. http://doi.org/10.1080/03075070902785580

Altunkaya, H., \& Topuzkanamış, E. (2018). The effect of using Facebook in writing education on writing achievement, attitude, anxiety and self-efficacy perception. Universal Journal of Educational Research, 6(10), 2133-2142. https://eric.ed.gov/contentdelivery/servlet/ERICServlet?accno=EJ1192723

Baker, V., \& Lattuca, L. (2010). Developmental networks and learning: Toward an interdisciplinary perspective on identity development during doctoral study. Studies in Higher Education, 35(7), 807827.

Baltes, B., Hoffman-Kipp, P., Lynn, L., \& Weltzer-Ward, L. (2010). Students' research self-efficacy during online doctoral research courses. Contemporary Issues in Education Research, 3(3), 51-58. https://eric.ed.gov/contentdelivery/servlet/ERICServlet?accno=EJ1072587

Bandura, A. (1986). Social foundations of thought and action: A social cognitive theory. Prentice-Hall.

Bandura, A. (1989). Human agency in social cognitive theory. American Psychologist, 44, 1175-1184. http://dx.doi.org/10.1037/0003-066X.44.9.1175.

Bandura, A. (1993). Perceived self-efficacy in cognitive development and functioning. Educational Psychologist, 28(2), 117-148.

Bandura, A. (2006). Guide for constructing self-efficacy scales. In F. Pajares \& T. Urdan (Eds.), Self-efficacy beliefs of adolescents (pp. 307-337). Institute of Analysts and Programmers.

Bandura, A., Barbaranelli, C., Caprara, G. V., \& Pastorelli, C. (1996). Multifaceted impact of self-efficacy beliefs on academic functioning. Child Development, 67(3), 1206-1222.

Bieschke, K. J. (2006). Research self-efficacy beliefs and research outcome expectations: Implications for developing scientifically minded psychologists. Journal of Career Assessment, 14(1), 77-91. http://doi.org/10.1177/1069072705281366

Bishop, R. M., \& Bieschke, K. J. (1998). Applying social cognitive theory to interest in research among counseling psychology graduate students: A path analysis. Journal of Counseling Psychology, 45, 182-188.

Breitenbach, E. (2019). Evaluating a model to increase doctorate program completion rates: A focus on social connectedness and structure. International Journal of Doctoral Studies, 14, 217-236.

https://doi.org/10.28945/4239 
Brennan, N. M. (2019). $100 \mathrm{PhD}$ rules of the game to successfully complete a doctoral dissertation. Accounting, Auditing \& Accountability Journal, 32(1), 364-376.

Bruning, R., Dempsey, M., Kauffman, D. F., McKim, C., \& Zumbrunn, S. (2013). Examining dimensions of self-efficacy for writing. Journal of Educational Psychology, 105(1), 25-38. https://doi.org/10.1037/a0029692

Cone, J. D. \& Foster, S. L. (2006). Dissertations and theses from start to finish (2nd ed.). American Psychological Association.

Cuthbert, D., \& Spark, C. (2008). Getting a GRIP: Examining the outcomes of a pilot program to support graduate research students in writing for publication. Studies in Higher Education, 33(1), 77-88. https://doi.org/10.1080/03075070701794841

Ford, J. H. (2010). Academic support for doctoral students really does work! Evidence from a study of "proposal writing" workshops. In M. Kiley (Ed.), Proceedings of the 2010 Quality in Postgraduate Research Conference: Educating researchers for the 21st century (pp. 235-239). The Centre for Educational Development and Academic Methods, The Australian National University.

Gardner, S. K. (2009). The development of doctoral students: Phases of challenge and support (special report). ASHE Higher Education Report, 34(6), 1-127. https://doi.org/10.1002/aehe.3406

Hecht, J., \& Martocci, S. (2010). GroupMe [Mobile application software]. https://groupme.com/

Kamler, B. (2008). Rethinking doctoral publication practices: Writing from and beyond the thesis. Studies in Higher Education, 33(3), 283-294. https://doi.org/10.1080/03075070802049236

Kamler, B., \& Thomson, P. (2008). The failure of dissertation advice books: Toward alternative pedagogies for doctoral writing. Educational Researcher, 37(8), 507-514. https://doi.org/10.3102/0013189X08327390

Kozar, O., Lum, J. F., \& Benson, P. (2015). Self-efficacy and vicarious learning in doctoral studies at a distance. Distance Education, 36(3), 448-454. http://doi.org/10.1080/01587919.2015.1081739

Lambie, G. W., Hayes B. G., Griffith, C., Limberg, D., \& Mullen, P. R. (2016). An exploratory investigation of the research self-efficacy, interest in research, and research knowledge of $\mathrm{PhD}$ in education students. Innovations in High Education, 39, 139-153. https://doi.org/10.1007/s10755-013-9264-1

Lassig, C., Dillon, L., \& Diezmann, C. (2013). Student or scholar? Transforming identities through a research writing group. Studies in Continuing Education, 35(3), 299-315.

Lavelle, E. (2006). Teachers' self-efficacy for writing. Electronic Journal of Research in Educational Psychology, 4(1), 73-84.

Lee, A., \& Kamler, B. (2008). Bringing pedagogy to doctoral publishing. Teaching in Higher Education, 13(5), 511-523. http://doi.org/10.1080/13562510802334723

Lev, E. L., Kolassa, J., \& Bakken, L. L. (2010). Faculty mentors' and students' perceptions of students' research self-efficacy. Nurse Education Today, 30(2), 169-174. https://doi.org/10.1016/j.nedt.2009.07.007

Lloyd, T. S., D'Errico, E., \& Bristol, T. S. (2016). Use of the Iowa model of research in practice as a curriculum framework for Doctor of Nursing Practice (DNP) project completion. Nursing Education Perspectives, 37(1), 51-53. https://doi.org/10.5480/14-1364

Love, K. M., Bahner, A. D., Jones, L. N., \& Nilsson, J. E. (2007). An investigation of early research experience and research self-efficacy. Professional Psychology: Research and Practice, 38(3), 314-320. https://doi.org/10.1037/0735-7028.38.3.314 
Maher, D., Seaton, L., McMullen, C., Fitzgerald, T., Otsuji, E., \& Lee. A. (2008). "Becoming and being writers": The experiences of doctoral students in writing groups. Studies in Continuing Education, $30(3), 263-275$.

McCarthy, P., Meier, S., \& Rinderer, R. (1985). Self-efficacy and writing: A different view of self-evaluation. College Composition and Communication, 36, 465-471.

Overall, N. C., Deane, K. L., \& Peterson, E. R. (2011). Promoting doctoral students' research self-efficacy: Combining academic guidance with autonomy support. Higher Education Research and Development, 3o(6), 791-805. http://doi.org/10.1080/07294360.2010.535508

Pajares, F. (1997). Current directions in self-efficacy research. In M. Maehr \& P. R. Pintrich (Eds.), Advances in motivation and achievement (pp. 1-49). JAI Press.

Pajares, F., \& Valiante, G. (1999). Grade level and gender differences in the writing self-beliefs of middle school students. Contemporary Educational Psychology, 24(4), 390-405.

Plakhotnik, M. S., \& Rocco, T. S. (2016). Increasing writing self-efficacy of adult learners. Adult Learning, 27(4), 160-167. https://doi.org/10.1177/1045159515611879

Rockinson-Szapkiw, A. J., Spaulding, L. S., \& Spaulding, M. T. (2016). Identifying significant integration and institutional factors that predict online doctoral persistence. Internet \& Higher Education, 31, 101122. https://doi.org/10.1016/j.iheduc.2016.07.003

Russell-Pinson, L., \& Harris, M. L. (2017). Anguish and anxiety, stress and strain: Attending to writers' stress in the dissertation process. Journal of Second Language Writing, 43, 63-71. https://doi.org/10.1016/j.jslw.2017.11.005

Sanders-Reio, J., Alexander, P., Reio, T. G., \& Newman, I. (2014). Do students' beliefs about writing relate to their writing self-efficacy, apprehension, and performance? Learning and Instruction, 33, 1-11. https://doi.org/10.1037/t48320-000

Seaman, J. E, Allen, I. E., \& Seaman, J. (2018). Grade increase: Tracking distance education in the United States. http://www.onlinelearningsurvey.com/highered.html

Shea, P., \& Bidjerano, T. (2010). Learning presence: Towards a theory of self-efficacy, self-regulation, and the development of a communities of inquiry in online and blended learning environments. Computers and Education, 55(4), 1721-1731. https://doi.org/10.1016/j.compedu.2010.07.017

Stadtlander, L., Giles, M., \& Sickel, A. (2013). The virtual research lab: Research outcomes expectations, research knowledge, and the graduate student experience. Journal of Educational Research and Practice, 3(1), 120-138. https://doi.org/10.5590/JERAP.2013.03.1.08

Stadtlander, L., \& Sickel, A. (2017, July 14). Validation of the Doctoral Writing Knowledge and Efficacy Inventory. Poster presented at Walden University Summer Session, Washington, DC.

Stoilescu, D., \& McDougall, D. (2010). Starting to publish academic research as a doctoral student. International Journal of Doctoral Studies, 5, 79-92.

Treanor, M., \& Barry, T. J. (2017). Treatment of avoidance behavior as an adjunct to exposure therapy: Insights from modern learning theory. Behaviour Research and Therapy, 96, 30-36. https://doi.org/10.1016/j.brat.2017.04.009

Unrau, Y. A., \& Beck, A. R. (2004). Increasing research self-efficacy among students in professional academic programs. Innovative Higher Education, 28(3), 187-205. https://doi.org/10.1023/B:IHIE.0000015107.51904.95 
Walder, G. E., Golde, C. M., Jones, L., Bueschel, A. C., \& Hutchings, P. (2008). The formation of scholars: Rethinking doctoral education for the twenty-first century. The Carnegie Foundation for the Advancement of Teaching.

Wenger, E. (1998). Communities of practice: Learning as a social system. Systems Thinker, 9(5), 1-8.

Wenger, E., \& Snyder, W. (2000). Communities of practice: The organizational frontier. Harvard Business Review, 78(1), 139-146.

The Higher Learning Research Communications (HLRC), is a peer-reviewed, online, interdisciplinary journal indexed in Scopus, ERIC, JGATE and Directory of Open Access Journals (DOAJ). It is an open access journal with an international focus published by Walden University, USA. Its aim is to disseminate both high quality research and teaching best practices in tertiary education across cultures and disciplines. HLRC connects the ways research and best practice contribute to the public good and impact the communities that educators serve. $H L R C$ articles include peer-reviewed research reports, research briefs, comprehensive literature reviews, and books reviews. 